\title{
Paced Rhythm
}

National Cancer Institute

\section{Source}

National Cancer Institute. Paced Rhythm. NCI Thesaurus. Code C88140.

An electrocardiog raphic finding in which the cardiac rhythm is controlled by an electrical impulse from an artificial cardiac pacemaker. (CDISC) 